\title{
Valores de referência para hemograma de cabras (Capra hircus) da raça Saanen criadas no município de Londrina/PR
}

Marcela dos Santos Ribeiro, Isadora Naomi Vieira Ogawa, Juliana Joaquim da Silva, Ariane Gerber Aleixo dos Reis, Gustavo Rodrigues Queiroz, Aline Tramontini Zanluchi Queiroz*

Universidade Norte do Paraná (UNOPAR) Londrina, PR, Brasil

*Autor correspondente

e-mail: alinetramontinizanluchi@gmail.com

\section{Resumo}

O hemograma é uma ferramenta importante para a avaliação das enfermidades que acometem as espécies domésticas, no entanto existem poucos estudos sobre os parâmetros hematológicos nas diferentes faixas etárias de caprinos criados na região norte do Paraná. O objetivo desse estudo foi avaliar o perfil hematológico de cabras (Capra hircus) da raça Saanen em grupos etários diferentes, de forma a se obter valores para referência em animais criados nessa região. Os animais foram submetidos a exames clínicos previamente às coletas de sangue, de forma a avaliar a higidez e incluir apenas os animais saudáveis no estudo. Os grupos formados foram: cabras adultas com idades entre dois e meio e oito anos ( $n=27)$, cabritos lactentes com idades entre um e quatro meses $(n=10)$ e cabras com idades de cinco a sete meses $(n=13)$. Foram coletadas amostras de sangue por punção da veia jugular e estas amostras foram acondicionadas em frascos com EDTA. O exame hematológico consistiu na determinação do hematócrito, contagem de hemácias, concentração de hemoglobina, volume celular médio (VCM), concentração de hemoglobina celular média (CHCM), proteínas plasmáticas totais (PPT), fibrinogênio, contagem total de leucócitos e contagem diferencial de leucócitos. Os valores hematológicos obtidos para o grupo formado pelas cabras adultas foram: hematócrito 33,6 \pm 6,6\%, contagem de hemácias,16,1 $\pm 4,9 \times 10^{6} / \mathrm{mm}^{3}$, hemoglobina 13,6 $\pm 2,6 \mathrm{~g} / \mathrm{dL}$, VCM 22,6 $\pm 8,3 \mathrm{fL}$, CHCM, 40,9 \pm 4,2\%, PPT 7,0 $\pm 7,8 \mathrm{~g} / \mathrm{dL}$, fibrinogênio $326 \pm 113 \mathrm{mg} / \mathrm{dL}$, contagem total de leucócitos $10.600 \pm 4.731 / \mathrm{mm}^{3}$, neutrófilos bastonetes $24 \pm 62 / \mathrm{mm}^{3}$, neutrófilos segmentados $5.932 \pm 3.286 / \mathrm{mm}^{3}$, linfócitos $4.619 \pm 2.599 / \mathrm{mm}^{3}$, monócitos $275 \pm 710 / \mathrm{mm}^{3}$, eosinófilos $129 \pm 161 / \mathrm{mm}^{3}$, basófilos $0 \pm 0 / \mathrm{mm}^{3}$. Os valores hematológicos obtidos para o grupo formado pelos cabritos lactentes foram: hematócrito 33,2 $\pm 7,1 \%$, contagem de hemácias $12,7 \pm 2,7 \times 10^{6} / \mathrm{mm}^{3}$, hemoglobina 13,4 $\pm 2,0 \mathrm{~g} / \mathrm{dL}$, VCM 26,6 \pm 4,6 fL, CHCM 41,1 \pm 4,2\%, PPT 5,4 \pm 0,5g/dL, fibrinogênio $240 \pm 111 \mathrm{mg} / \mathrm{dL}$, contagem total de leucócitos $15.940 \pm$ $4.424 / \mathrm{mm}^{3}$, neutrófilos bastonetes $165 \pm 133 / \mathrm{mm}^{3}$, neutrófilos segmentados $6.511 \pm 3.270 / \mathrm{mm}^{3}$, linfócitos 
$8.932 \pm 4.297 / \mathrm{mm}^{3}$, monócitos $266 \pm 253 / \mathrm{mm}^{3}$, eosinófilos $65 \pm 135 / \mathrm{mm}^{3}$, basófilos $0 \pm 0 / \mathrm{mm}^{3}$. Os valores hematológicos obtidos para o grupo formado pelas cabras com idades entre 5 e 7 meses foram: hematócrito $34,4 \pm 4,6 \%$, contagem de hemácias $20,1 \pm 3,5 \times 10^{6} / \mathrm{mm}^{3}$, hemoglobina $12,6 \pm 1,9 \mathrm{~g} / \mathrm{dL}$, VCM 18,0 $\pm 2,6 \mathrm{fL}$, CHCM 37,9 $\pm 3,0 \%$, PPT 5,9 $\pm 0,6 \mathrm{~g} / \mathrm{dL}$, fibrinogênio $323 \pm 197 \mathrm{mg} / \mathrm{dL}$, contagem total de leucócitos 14.469 $\pm 3.457 / \mathrm{mm}^{3}$, neutrófilos bastonetes $41 \pm 76 / \mathrm{mm}^{3}$, neutrófilos segmentados $4.394 \pm 1.617 / \mathrm{mm}^{3}$, linfócitos $9.763 \pm 2.618 / \mathrm{mm}^{3}$, monócitos $224 \pm 206 / \mathrm{mm}^{3}$, eosinófilos $47 \pm 73 / \mathrm{mm}^{3}$, basófilos $0 \pm 0 / \mathrm{mm}^{3}$. A análise estatística destes resultados permite estabelecer valores de referência para os parâmetros hematológicos de caprinos da raça Saanen criados no norte do Paraná, em condições semelhantes de clima e de manejo nutricional. 